${ }^{1}$ Immunology and ${ }^{2}$ Developmental Neurobiology, Faculty of Sciences, Department of Biology, University of Konstanz, Konstanz, Germany and ${ }^{3}$ Biotechnologie Institut Thurgau, Tägerwilen, Switzerland

\title{
The Lipid Raft Microdomain-Associated Protein Reggie-1/ Flotillin-2 is Expressed in Human B Cells and Localized at the Plasma Membrane and Centrosome in PBMCs
}

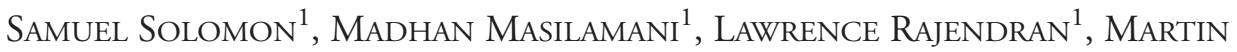 \\ Bastmeyer $^{2}$, Claudia A. O. Stuermer ${ }^{2}$, and Harald Illges ${ }^{1,3}$
}

Received November 23, 2000 . Accepted in revised form November 26, 2001

\begin{abstract}
Reggie-1/flotillin-2 is a plasma membrane-associated cytoplasmic protein, which defines non-caveolar raft microdomains. Reggie-1/flotillin-2 is enriched in detergent insoluble (TX100) membrane fractions (DIG), co-localizes with activated GPI-linked proteins and the fyn-kinase in neurons and T cells, and thus apparently participates in the assembly of protein complexes essential for signal transduction. In $\mathrm{T}$ cells activated by crosslinking the GPI-linked protein Thy- 1 or by crosslinking the ganglioside GM1, reggie-1/flotillin-2 co-localizes with the $\mathrm{T}$ cell receptor. To determine whether reggie-1/flotillin-2 is also expressed in B cells, primary B cells from human blood and cell lines representing the developmental stages of pro, pre, mature and plasma B cells were analyzed by Western blotting, RT-PCR and immunofluorescence. Here, we show that reggie-1/flotillin-2 is expressed throughout B cell development, as well as in primary B cells, purified by cell sorting. On non-activated mature B cell Raji cell line we found reggie-1/flotillin-2 are exclusively in the detergent (TX100) insoluble membrane fractions that are staining positive for the raft marker GM1. Immunofluorescence microscopy showed that reggie- $1 /$ flotillin-2 is localized at the plasma membrane and marks intracellular spots in PBMCs. Confocal co-localization studies showed that reggie-1/flotillin-2 is associated with the plasma membrane, and the centrosomes (microtubule organizing centers) in these PBMCs. Comparison of reggie-1/flotillin-2 cDNA sequences with the genomic sequence database allowed us to determine the exon/intron structures in mouse and human. The gene organizations are highly conserved suggesting an important function of reggie-1/flotillin-2. Since reggie/flotillin proteins co-cluster with the $\mathrm{T}$ cell receptor and fyn kinases upon $\mathrm{T}$ cell stimulation, our findings of reggie-1/flotillin-2 in B cells suggest a similar role in B cell function.
\end{abstract}

\section{Introduction}

The cellular plasma membrane is structured and possesses, next to other specialized regions, so-called lipid raft microdomains (1). They act as platforms for the assembly of receptors and components of signal transduction cascades and include proteins with 
lipid raft affinity such as glycosylphosphatidylinositol (GPI)-anchored cell surface proteins of the plasma membrane and G-proteins and src-family tyrosine kinases at the cytoplasmic face (1). Signaling across the plasma membrane is thus mediated by the concentration and concerted interaction of proteins assembling in such raft microdomains. Raft microdomains are quite conspicuous in hematopoietic cells where clustering of signaling molecules is a pre-requisite for cell activation (2-5). In activated T cells, the GPIlinked surface protein Thy-1, fyn kinase and T cell receptor (TCR) components co-cluster in raft microdomains. More recently, it was recognized that these co-clusters contain the reggie-1/flotillin-2 protein (6).

The gene encoding this protein was cloned in goldfish, zebra fish and rats and termed reggie-1 (7-9). A homologous gene was also identified in mouse and human and the encoded protein was termed flotillin-2 (10). Reggie-1/flotillin-2 is identical to epidermal surface antigen (ESA) isolated from murine keratinocytes which, however, lacks the first 47 amino acids (11) and is recognized by the monoclonal antibody ESA. Reggie-1/ flotillin-2 belongs to a family of evolutionary highly conserved genes (9) and is expressed in various cell types, i.e., adipocytes, fibroblasts, endothelial cells, neurons, glial cells as well as in cell lines representing kidney, smooth muscle, and erythrocytes but not in skeletal muscle (12). Reggie-1 and -2 are found in retina ganglion cells of rats and fish, various other neurons and glial cells as well as in human T cells $(8,9)$. Recently reggie-1/flotillin-2 has been found to be one of the major components in erythrocyte lipid rafts (13).

Since activated GPI-anchored surface proteins co-clusters with reggie and src-family tyrosine kinases, it may participate in raft microdomain-associated signal transduction events, in neurons and T cells, and may thus be of functional relevance for B cells too. To address this point, we determined the expression and localization of reggie-1/flotillin-2 in B lymphoid cells studying cell lines representing distinct stages of human B cell development (pro-, pre-, mature-, and plasma-B cells) as well as in sorted primary $\mathrm{CD} 19^{+} \mathrm{B}$ cells from peripheral blood. All cells express reggie-1/flotillin-2 mRNA and protein and reggie reside in rafts on the plasma membrane. Using confocal laser scanning microscopy we observed reggie-1/flotillin-2 associated with the plasma membrane in the cells and also with centrosomes in PBMCs. Furthermore, database analysis allowed us to determine the gene structure of reggie-1/flotillin- 2 for the mouse and human locus. The reggie-1/flotillin-2 gene organization is highly conserved with all the intron/exon boundaries following the GT/AG rule and with splice sites located at the exactly similar base pairs in the murine and the human genome.

\section{Materials and Methods}

cDNA synthesis and RT-PCR analysis

The quality of the prepared RNA was verified by gel electrophoresis. $5 \mu \mathrm{g}$ of RNA was used to synthesize cDNA according to the manufacturers protocol (GibcoBRL, Eggenstein, Germany). The quality of the synthesized cDNA was controlled by RT-PCR amplification of GAPDH using primers KN-45 (CCA CCCATG GCAAAT TCCATG GCA) and KN-46 (TCT AGA CGG CAG GTCAGG TCCACC). Reggie-1/flotillin-2 expression was tested by RT-PCR amplification using primers: KN162 Forward 5'CTTTAACTG TGA CGG GTG TC 3'; KN170 Reverse: 5’AAG GCT CGCTTA 
GAGTCAGC 3'; KN169 Forward: 5' CTGACTCTAAGCGAGCCTTC 3'; KN163 Reverse: $5^{\prime}$ TATCTTAGACAGGTCCACGC 3'. The PCR-conditions were $94^{\circ} \mathrm{C}, 45 \mathrm{sec}$.; $50^{\circ} \mathrm{C}, 1 \mathrm{~min}$; $72^{\circ} \mathrm{C}, 45$ sec.; 35 cycles for both primer pairs.

Preparation of cells, cell lines

Human peripheral blood mononuclear cells (PBMC) were isolated from buffy coats of healthy blood donors by Ficoll-Isopaque (Pharmacia, Uppsala, Sweden) density gradient centrifugation. The pro B cell line KM3 (14), the pre B cell line Nalm6 (15), the mature B cell lines RAJI (16) and DAKIKI (17) and the plasma B cell line HS Sultan (18) were maintained in Iscoves modified Dulbeccos medium (GibcoBRL, Eggenstein, Germany). The medium was supplemented with $10 \%$ fetal bovine serum, $3024 \mathrm{mg} / \mathrm{l}$ sodium bicarbonate, $100 \mathrm{U} / \mathrm{ml}$ penicillin and $100 \mu \mathrm{g} / \mathrm{ml}$ streptomycin.

\section{Western blotting}

Cell lysates were prepared using Nonidet P-40 lysis buffer (1\% Nonidet P-40, 10 mM Tris-pH 7.4, $150 \mathrm{mM} \mathrm{NaCl}$ ) with protease inhibitors $(50 \mu \mathrm{g} / \mathrm{ml}$ aprotinin, $10 \mu \mathrm{g} / \mathrm{ml}$ leupeptin, $50 \mu \mathrm{g} / \mathrm{ml}$ pepstatin A, $1 \mathrm{mM}$ PMSF). Extracted proteins were resolved on a 10\% SDS-PAGE gels under reducing conditions, and transferred to nitro-cellulose. Reggie-1/flotillin-2 was detected with the monoclonal antibody ESA (Transduction Laboratories, BD Biosciences, Heidelberg, Germany) followed by a peroxidase-labeled goat anti-mouse antibody (Pierce, USA). Immunoblots were developed with enhanced chemiluminescence reagent (ECL; Amersham Corporation). The lipid raft soluble and insoluble fractions were subjected to a reducing $4-12 \%$ gradient SDS-PAGE and then blotted onto nitro-cellulose membrane. The blots were then probed for the presence of reggie-1/flotillin-2with ESA mAB, GM1 by cholera toxin subunit B conjugated to HRP (Sigma, Germany) and BCR by goat anti human IgM conjugated to HRP (Jackson Laboratories, USA).

\section{Isolation of lipid rafts}

$10^{8}$ cells were lysed for 30 minutes in cold in TNE $(10 \mathrm{mM}$ Tris $\mathrm{HCl}, \mathrm{pH} 7.5,150 \mathrm{mM} \mathrm{NaCl}$, and $5 \mathrm{mM}$ EDTA) buffer with $1 \%$ Triton X-100, protease and phosphatase inhibitors. The solution after lysis was further homogenized with ten strokes in a loose fitting dounce homogenizer and centrifuged at $900 \mathrm{~g}$ for 10 minutes. $1 \mathrm{ml}$ of the cleared supernatant was mixed with $85 \%$ sucrose in TNE buffer and layered at the bottom of a Beckman $12 \mathrm{ml}$ centrifuge tube. The lysate was overlaid with $6 \mathrm{ml}$ of $35 \%$ sucrose in TNE buffer and finally with $3.5 \mathrm{ml}$ of $5 \%$ sucrose in TNE buffer. The samples were centrifuged in a SW41 rotor at $200,000 \mathrm{~g}$ for $20 \mathrm{~h}$ at $4{ }^{\circ} \mathrm{C}$. At the end of the run, $1 \mathrm{ml}$ fractions were collected from the top of the gradient. $15 \mu \mathrm{l}$ from each of the fractions was boiled with SDS buffer and subjected to a reducing $4-12 \%$ gradient SDS PAGE and western blotting analysis.

\section{Separation of B cells from PBMC by magnetic-activated cell sorting (MACS)}

Purified PBMC were stained with CD19-specific antibodies coupled to paramagnetic beads and separated with MACS (19) according to the manufacturers instructions (Miltenyi Biotec GmbH, Germany). The purity of the sorted cells was verified by flow cytometry analysis using a FACScan (Becton Dickenson, Heidelberg, Germany) and a loader allowing the use of microtiter plates for acquisition of cells (20).

\section{Immunostaining}

For immunocytochemistry cells were centrifuged onto cover slips using a Hettich Rotifix 32 microcentrifuge with a Zyto-System rotor (Hettich, Tuttlingen, Germany). Cells were fixed with ice-cold methanol $\left(-20^{\circ} \mathrm{C}, 5 \mathrm{~min}\right)$ and in $2 \%$ formaldehyde (RT, $10 \mathrm{~min}$ in phosphate buffer) and after 3 washes in PBS incubated with the ESA mAB (1:125 in PBS containing 1\% Bovine Serum Albumin overnight at $\left.4^{\circ} \mathrm{C}\right)$. After 3 washes in PBS (10 min each), cells were treated with secondary antibodies (goat anti-mouse Cy3, Dianova, Hamburg, Germany) for $2 \mathrm{~h}$ at RT. Cells were washed in PBS ( $3 \times$ 
$10 \mathrm{~min})$, incubated in DAPI $(0.5 \mu \mathrm{g} / \mathrm{ml})$ for $10 \mathrm{~min}$ to visualize cell nuclei and mounted in a mixture of Mowiol (Hoechst, Germany), PBS and glycerol with n-propyl-gallate as an anti-fading agent. For double immunostainings, cells were exposed to ESA mAB, anti- $\beta$-tubulin pAB (Sigma, Germany) and counterstained with appropriate secondary antibodies (goat anti-mouse Alexa- 488 and goat anti-rabbit $\mathrm{Cy} 3$ respectively). Labeled cells were viewed in a fluorescence microscope (Zeiss Axioplan) using a $100 \times$ lens and the appropriate filter set. Pictures were taken with a digital camera (Digital Instruments, KAF-1401E CCD) under identical camera settings and 12 BIT pixel depth using MetaMorph software and images processed with Adobe Photoshop software. Selected cells were analyzed with laser scanning confocal microscopy (LSM 510, Zeiss).

\section{Results}

The gene structure of reggie-1/flotillin-2 is conserved between mouse and human

To design oligonucleotides for RT-PCR from the reggie-1/flotillin-2 gene, we analyzed candidates by database comparison for redundancy. During this process we found the complete unaligned working draft of the human and murine reggie-1/flotillin-2 locus. We used this data and the cDNA sequence to construct the gene organization of reggie-1/ flotillin-2 in mouse and human. Figure 1 shows the map of the human, murine and drosophila gene. The sequence comparison was done with the corresponding cDNA sequences (accession codes NM 004475 from human, NM 008028 from mouse and AF044916-bases 136073-144136 from Drosophila melanogaster) against their genomic DNA sequence (AC024267, AC048361 and AE003497 respectively) using BLAST alignment program. The human flotillin-2 gene is localized on chromosome 17 and the murine gene on mouse chromosome 11. Interestingly, the alignment showed that both human and mouse used the exact splice sites throughout the entire gene. Furthermore, the size and distribution of coding exons and introns is highly conserved between both species. The human gene is comprised of 11 and the murine gene of 12 exons. The first two exons of the human and the first 3 exons of the murine gene are non-coding and are spliced onto the ATG start codon in exon 3 and exon 4, respectively. All the coding exon/intron boundaries followed the GT/AG rule of splice junction sequences. The length of intron 5 of the murine gene could not be specified because the sequences of this region are split into two contigs, which are not yet aligned. The structure of the Drosophila melanogaster gene, although carrying 65\% amino acid identity, is different in several respects. The $5^{\prime}$ untranslated region is not spliced, the ATG start codon is therefore in the first exon and the gene consists of only 5 exons. In the fly, exon 5-8 and $10-11$ of the human and mouse genes are comprised into a single exon. As expected, the coding exons of mouse and man are $>87 \%$ identical when compared to each other (21). When we analyzed the $5^{\prime}$ non-coding exons, we found differences between the mice and human genes. Up to now we found 3 non-coding exons in the murine genome and 2 non-coding exons in the human genome based on database searches. Exon 2 of mice and the human exon 2 share $92 \%$ identity. The murine exon 3 has no similarity to any part of the human gene. Thus it represents an insertion into the murine or is deleted in the human genome. The human exon 1 is similar to exon 1 of mice. Based on our analysis, the human reggie-1/flotillin-2 gene promoter is at least $10 \mathrm{~kb} 5^{\prime}$ of the ATG translational start codon. 

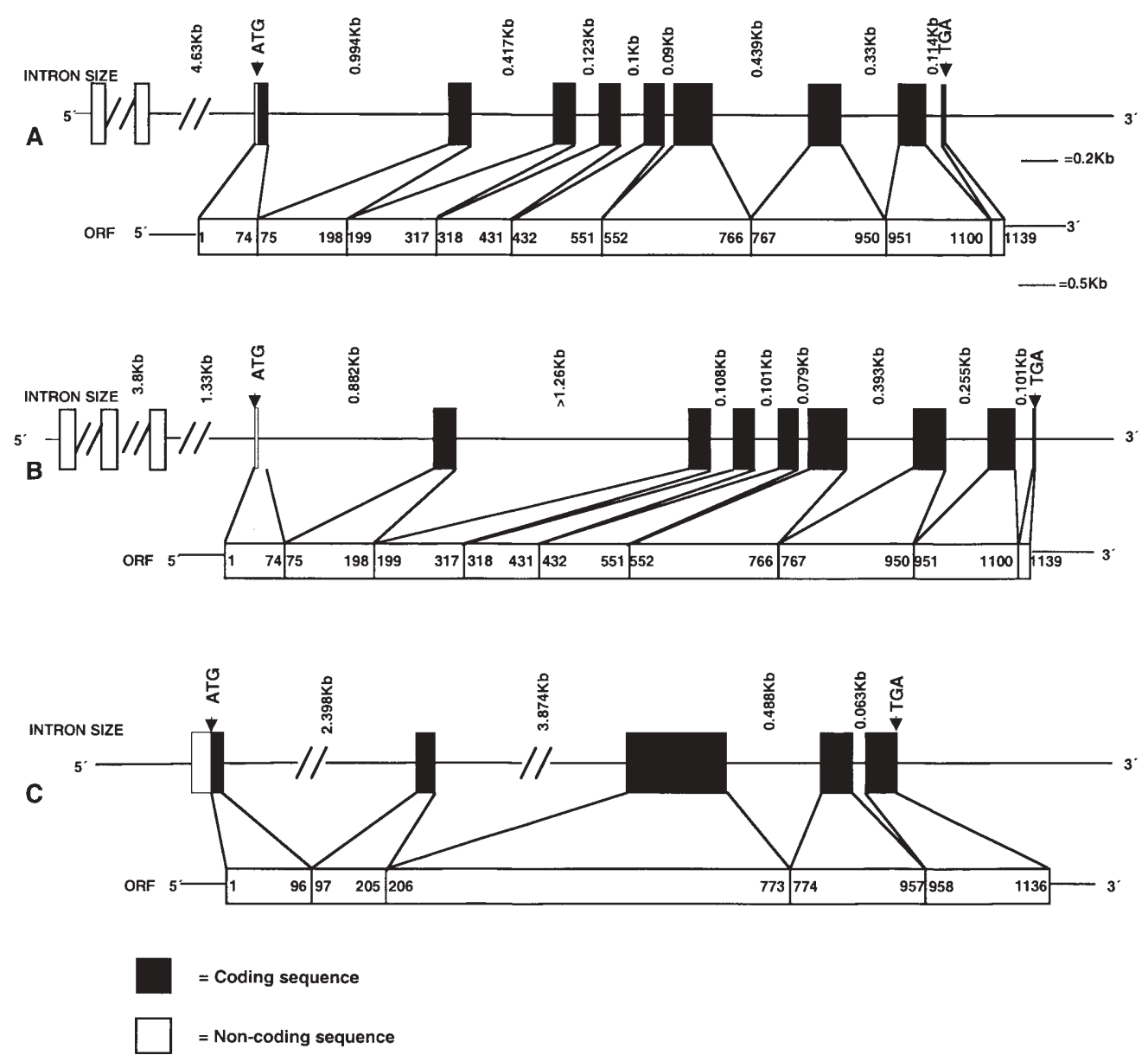

Figure 1. The structure of human (A), mouse (B) and Drosophila melanogaster (C) genes encoding reggie-1/flotillin-2.

RT-PCR and Western blotting shows expression of reggie-1/flotillin-2 in B cells

Oligonucleotides derived from the human flotillin-2 cDNA sequence were used to perform RT-PCR analysis of the cell lines KM3 (pro B cell stage), Nalm6 (pre B cell stage), Dakiki, Raji (both mature B cell stage) and HS Sultan (plasma B cell stage). According to this analysis all cell types transcribed the reggie-1/flotillin-2 gene (Fig. 2). Moreover, the RT-PCR analysis gave no evidence for alternative splicing as only the bands of the expected size were detected. To analyze whether primary B cells also transcribe the reggie-1 gene, we sorted $\mathrm{CD} 19^{+}$cells from ficoll density gradient purified buffy coats by magnetic sorting (19). These purified B cells from blood also showed expression of the reggie-1/flotillin-2 mRNA as revealed by RT-PCR (Fig. 2). 


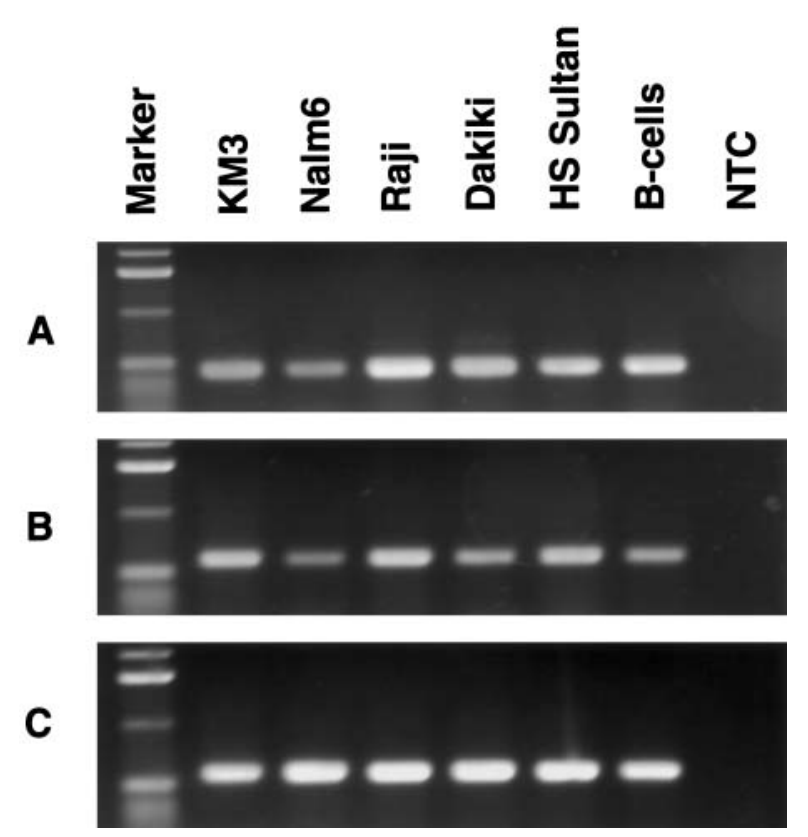

Figure 2. Reggie-1/flotillin-2 gene expression in B cells. The reggie-1/flotillin-2 mRNA was identified by RT-PCR amplification. Oligonucleotides specific for exon 3/7 and exon 7/10 amplify a 460 bp (A) and a 614 bp band (B) respectively in the reggie-1/flotillin-2 gene. All cell lines express the flotillin-2 gene as indicated by the $460 \mathrm{bp}$ and $614 \mathrm{bp}$ bands. These results also show absence of significant alternative splicing. GAPDH RT-PCR (C) was used as internal control. No template control was used as negative control (NTC).

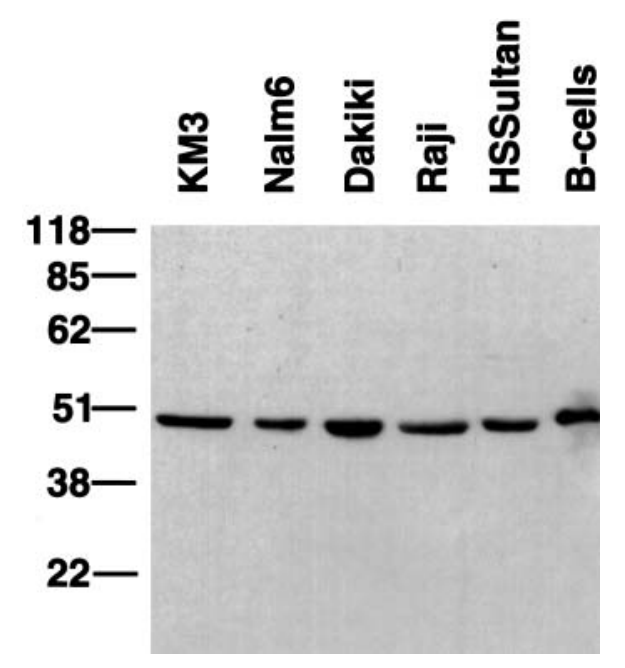

Figure 3. Reggie-1/flotillin-2 protein expression in B cells. Protein extracts from $2 \times 10^{5}$ cells were loaded per lane. Immunoblots were performed after 10\% SDS-PAGE using ESA antibody. The ESA antibody detects the $48 \mathrm{kDa}$ reggie-1/flotillin-2 protein in $\mathrm{B}$ cells. 
To assess whether the corresponding reggie-1/flotillin-2 protein is expressed in the cell lines and the sorted primary B cells, we performed Western blot analysis with the ESA antibody that recognizes reggie-1/flotillin-2 (8). In line with our RT-PCR data, reggie-1/ flotillin-2 protein is expressed in all the cells analyzed and occurs as a single band with a molecular weight of $48 \mathrm{kDa}$ (Fig. 3).

Reggie-1 / flotillin-2 resides exclusively in raft fractions of non-stimulated B cells

Reggie-1/flotillin-2 is known to be a plasma membrane, non-caveolar raft microdomain associated protein. To determine if this is also the case in B cells, we isolated detergent (TX100) insoluble membrane fractions on a sucrose gradient from non-activated Raji cells, representing the mature stage of development. Reggie-1/flotillin-2 was present (Fig. 4) exclusively in the sucrose gradient fractions staining positive for the raft marker GM1. The IgM (B cell receptor) resides exclusively in the detergent soluble non-raft fraction in these non-activated $\mathrm{B}$ cells.

\section{$\begin{array}{lllllllllllll}1 & 2 & 3 & 4 & 5 & 6 & 7 & 8 & 9 & 10 & 11 & 12\end{array}$}

\section{Flotillin-2}

\section{BCR}

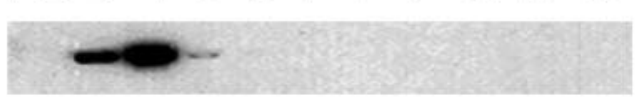

\section{GM1}

Figure 4. Reggie-1/flotillin-2 resides in B cell rafts. $10^{8}$ Raji B-Cells were lysed in $1 \%$ Triton X-100 containing TNE buffer (10 mM Tris, $150 \mathrm{mM} \mathrm{NaCl}, 5 \mathrm{mM}$ EDTA) and the cleared lysate was subjected to discontinuous sucrose gradient centrifugation and $15 \mathrm{ul}$ of each fraction from the top of the gradient was loaded onto a 4-12\% gradient gel and blotted onto a nitro-cellulose membrane. After transfer, the blot was probed for the presence of reggie-1/flotillin-2 by using $\mathrm{mAB}$ ESA and for IgM using anti-IgM conjugated to HRP. The ganglioside GM1 was detected by using Cholera toxin B subunit conjugated to HRP.

\section{Localization of reggie-1/flotillin-2 protein by immunofluorescence}

To investigate whether the reggie-1/flotillin-2 protein is associated with the plasma membrane of human B cells, as is the case in T cells and other cell types $(6,8,9)$, cells were subjected to immunofluorescence analysis and counter-stained with DAPI to visualise the nucleus. All cells exhibited immunoreactivity associated with the plasma membrane (Fig. 5) that often appeared punctate as previously described for neurons and glial cells (8). Where cells are in contact with neighboring cells (in KM3, Dakiki and Raji lines) (Fig. $6 \mathrm{a}$ and $6 \mathrm{~b}$ ), the plasma membrane staining is particularly evident and is reminiscent of the pattern seen in PC-12 cells (6). Confocal analysis verified the mem- 


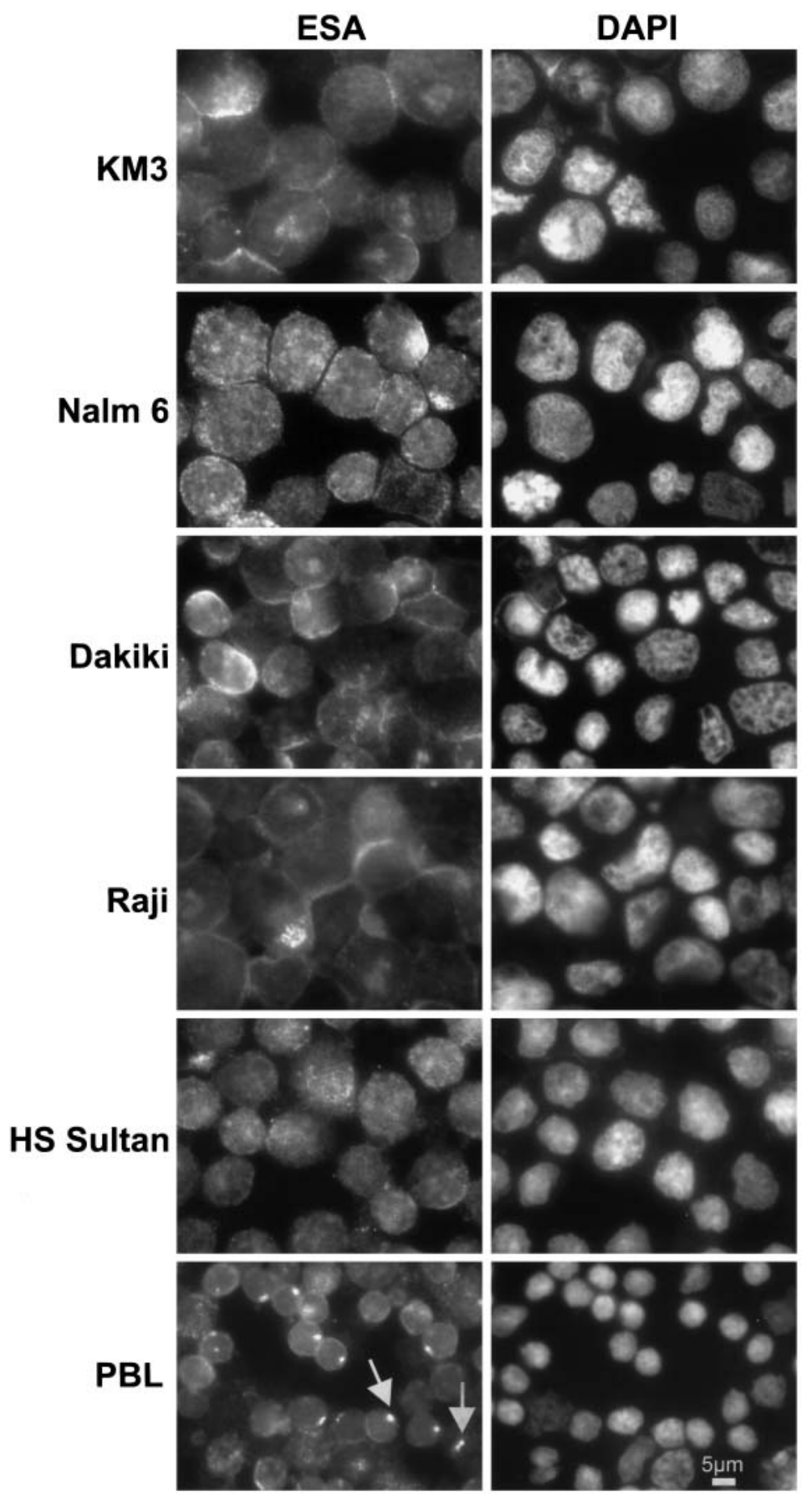

Figure 5. Detection of reggie-1/flotillin-2 by fluorescence microscopy. The left panel shows staining with the ESA monoclonal antibody. Staining of the nuclei (right panel) was done with DAPI. The arrows indicate intracellular staining in PBL. Scale bar, $5 \mu \mathrm{m}$. 

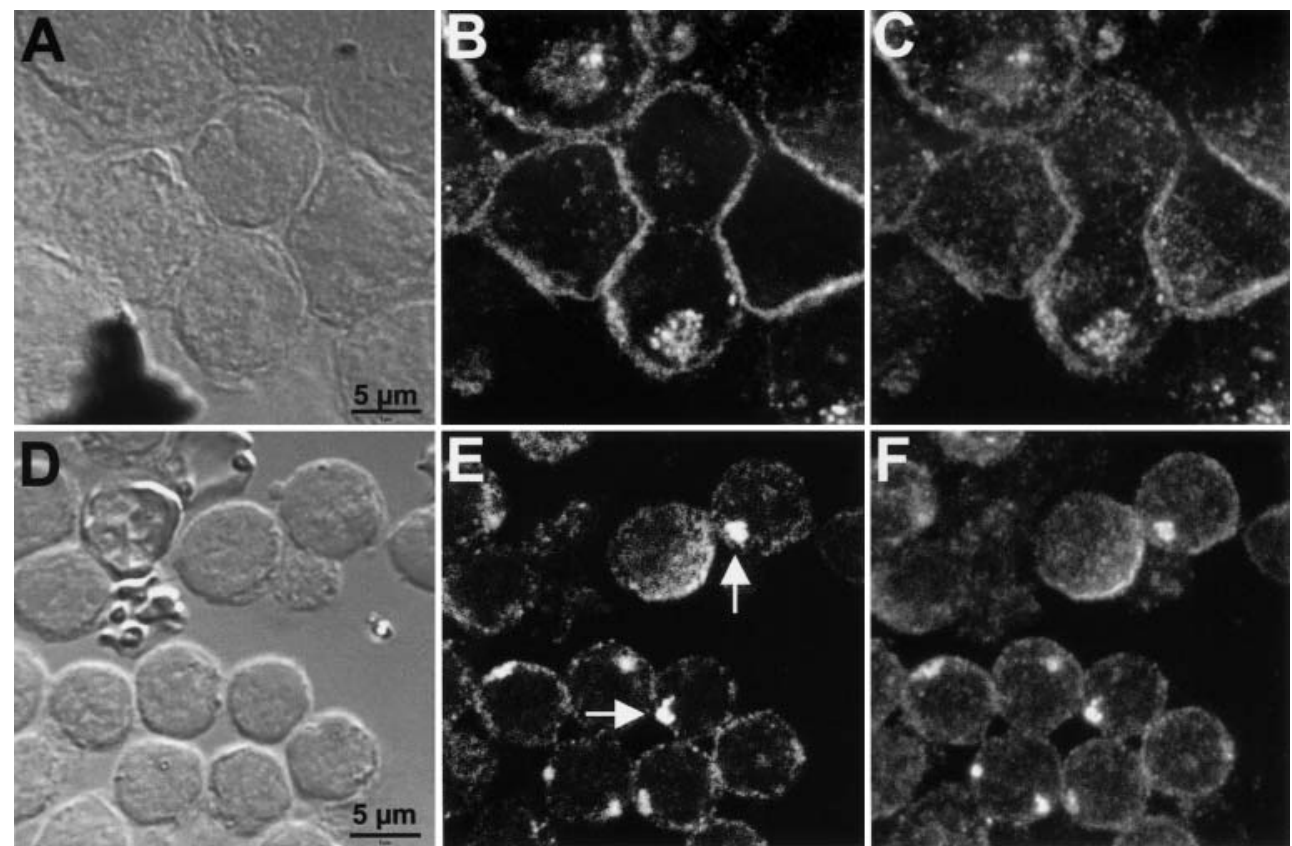

Figure 6a. Determination of reggie-1/flotillin-2 immunofluorescence by confocal microscopy. In Dakiki cells $(\mathrm{A}-\mathrm{C})$ and PBMC (D-F). Left panel $(\mathrm{A}+\mathrm{D})$, differential interference contrast, central panel $(\mathrm{B}+\mathrm{E})$ staining acquired in one optical section, and right panel $(\mathrm{C}+\mathrm{F})$ projection of 6 optical sections through all levels. Both samples display membrane-associated reggie-1/flotillin-2 staining. In addition PBMC show a spotted staining reminiscent of centrosomes (arrow). Scale bar, $5 \mu \mathrm{m}$.
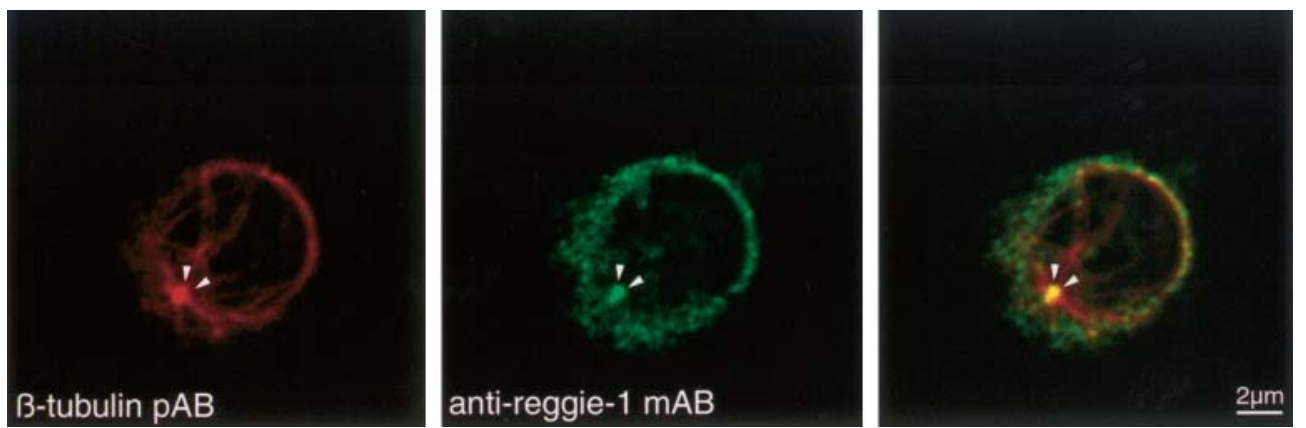

Figure 6b. Localization of reggie-1/flotillin-2 in cell membrane and centrosome. Human peripheral blood B cells were stained with antibodies against $\beta$-tubulin (left panel-red) and ESA (middle panelgreen). Confocal images were obtained as described in Materials and Methods. The figure on the right panel is the superimposed image of two stainings showing the co-localization of reggie-1/flotillin-2 and $\beta$-tubulin in the centrosome seen as a yellow spot. In addition to centrosomal localization, the protein is also found at the plasma membrane. 
brane-associated staining of reggie-1/flotillin-2 in Dakiki and PBMC (Fig. 6a, C and F). In addition of the PBMC cells had a single strongly stained spot (Fig. 6a).

Confocal co-localization studies with anti- $\beta$-tubulin and ESA mAB suggests that reggie-1/flotillin-2, apart from residing at the plasma membrane, is associated with centrosomes in PBMCs (Fig. 6b).

\section{Discussion}

Reggie-1/flotillin-2 belongs to a family of proteins conserved among distant species such as, flies, fish and mammals $(8-10,22,23)$. The evolutionary conservation of reggie-1/ flotillin-2 suggests a conserved function in these species including humans.

Recently, these proteins were found to share the newly discovered SPFH (stomatins, prohibitins, flotillins and $\mathrm{H} f \mathrm{~K} / \mathrm{C}$ ) domain with proteins from evolutionarily distant species such as bacteria $(\mathrm{Hfl} / \mathrm{K} / \mathrm{C})(24)$. This domain is implied to be involved in the modulation of protease activity after bacteriophage infection in prokaryotes and in the regulation of membrane-associated protein degradation in eukaryotes (24). Moreover, mutations in the SPFH domains in the C. elegans MEC-2, UNC-1 and UNC-24 genes disrupt functions related to mechanical signaling, locomotion, anesthetic, and osmotic sensitivity (24). Interestingly, the reggie /flotillin proteins were observed in endo-lysosomes most likely involved in protein degradation (6) indicating they are not only involved in raft microdomain-associated signalling but in intracellular trafficking probably to terminate signal transduction events.

In the hematopoietic lineages, rafts are well-established domains where signaling components meet upon activation and exert their function (25). Accordingly, the B cell receptor components occur in lipid rafts after cell activation $(2,3,5)$. Previous work demonstrated the presence of reggie-1/flotillin-2 in lipid raft microdomains $(8,10)$, and in association with the TCR, crosslinked Thy- 1 and fyn kinase in activated T cells (6). Here, we demonstrate expression of the reggie-1/flotillin-2 gene in human in primary $\mathrm{B}$ cells from blood and in cell lines representing various developmental stages of B cell differentiation. We further show the association of reggie-1/flotillin-2 with the B cell plasma membrane. Our analysis of the exon/intron structure of the human and mouse reggie-1/flotillin-2 genes provides further evidence for a remarkably strong conservation. Reggie-1 together with reggie-2, its related companion $(6,8)$, appear to demarcate sites for the accumulation of activated GPI-linked cell surface proteins in neurons and astrocytes, and they define raft microdomains, distinct from caveolae. This undoubtedly applies similarly to $\mathrm{T}$ and $\mathrm{B}$ cells as these cells much as neurons do not express caveolin nor do they form caveolae (25). This characterizes reggie-1/flotillin-2 as a non-caveolar raft-associated protein and suggests that it participates in the organization of raft microdomains and/or signal transduction initiated therein. We show here by raft isolation and immunoblot analysis that reggie-1/flotillin-2 resides exclusively in raft fractions defined by GM1 in non-activated Raji B cells.

While PBMC (resting cells) show membrane-associated staining with the ESA antibody, about $50 \%$ of the cells display additionally one or two clearly stained intracellular spots, which by co-localization studies with $\beta$-tubulin and flotillin- 2 was found to be the centrosome. In the cell lines KM3, Dakiki and Raji, but not in Nalm6 and HS Sultan, 
anti-reggie-1/flotillin-2 staining is quite conspicuous where cells contact each other. Whether this implies dynamic clustering of the protein at contact sites or simply represents increased immunofluorescence due to the proximity of two cell membranes is presently under investigation. A similar phenomenon has been observed in PC-12 cells, which exhibit co-clustering of Thy-1 and reggie proteins at cell contact sites (6). We are currently also investigating whether this staining co-localizes with certain proteins involved in homotypic aggregation.

Taken together, our results showing expression of reggie-1/flotillin-2 in human B cells provides the basis for further studies on its functional contribution during B cell maturation and activation.

\section{Acknowledgements}

We would like to thank Edward Malaga-Trillo, Rolf Knippers, Cornelia Kolb and J. SCHWAB for critical reading of the manuscript and helpful discussion during the work. This work was supported by a grant from the Ministry of Science and Culture of the State of Baden-Württemberg to C. A. O. S., by grants Il32/2-1 of the Deutsche Forschungsgemeinschaft and the Hans-HenchStiftung to H. I.

\section{References}

1. Simons, K., and D. ToOmre. 2000. Lipid Rafts and Signal Transduction. Nature Reviews 1: 31.

2. Cheng, P. C., M. L. Dykstra, R. N. Mitchell, and S. K. Pierce. 1999. A role for lipid rafts in B cell antigen receptor signaling and antigen targeting. J. Exp. Med. 190: 1549.

3. Guo, B., R. M. Kato, M. Garcia-Lloret, M. I. Wahl, and D. J. Rawlings. 2000. Engagement of the human pre-B cell receptor generates a lipid raft-dependent calcium signaling complex. Immunity 13: 243.

4. Aman, M. J., and K. S. RaVichandran. 2000. A requirement for lipid rafts in B cell receptor induced $\mathrm{Ca}(2+)$ flux. Curr. Biol. 10: 393 .

5. Petrie, R. J., P. P. Schnetkamp, K. D. Patel, M. Awasthi-Kalia, and J. P. Deans. 2000. Transient translocation of the B cell receptor and Src homology 2 domain-containing inositol phosphatase to lipid rafts: evidence toward a role in calcium regulation. J. Immunol. 165: 1220.

6. Stuermer, C. A. O., D. M. Lang, F. Kirsch, M. Wiechers, S. O. Deninger, and H. PLATTNER. 2001. GPI-anchored proteins and fyn kinase assemble in non-caveolar plasmamembrane microdomains defined by reggie-1 and -2. Mol. Biol. Cell 10: 3031 .

7. Schulte, T., K. A. Paschke, U. Laessing, F. LotTspeich, and C. A. Stuermer. 1997. Reggie-1 and reggie-2, two cell surface proteins expressed by retinal ganglion cells during axon regeneration. Development 124: 577.

8. Lang, D. M., S. Lommel, M. Jung, R. Ankerhold, B. Petrausch, U. Laessing, M. F. Wiechers, H. Plattner, and C. A. O. Stuermer. 1998. Identification of reggie-1 and reggie-2 as plasmamembrane-associated proteins which cocluster with activated GPI-anchored cell adhesion molecules in non-caveolar micropatches in neurons. J. Neurobiol. 37: 502.

9. Malaga-Trillo, E., U. Laessing, D. M. Lang, A. Meyer, and C. A. O. Stuermer. 2001. Evolution of duplicated reggie genes in zebrafish and goldfish. J. Mol. Evol. In press.

10. Bickel, P. E., P. E. Scherer, J. E. Schnitzer, P. OH, M. P. Lisanti, and H. F. Lodish. 1997. Flotillin and epidermal surface antigen define a new family of caveolae-associated integral membrane proteins. J. Biol. Chem. 272: 13793.

11. Schroeder, W. T., S. Stewart-Galetka, S. Mandavilli, D. A. Parry, L. Goldsmith, and M. DUVIC. 1994. Cloning and characterization of a novel epidermal cell surface antigen (ESA). J. Biol. Chem. 269: 19983. 
12. Volonte, D., F. Galbiati, S. Li, K. Nishiyama, T. Okamoto, and M. P. Lisanti. 1999. Flotillins/cavatellins are differentially expressed in cells and tissues and form a hetero-oligomeric complex with caveolins in vivo. Characterization and epitope-mapping of a novel flotillin-1 monoclonal antibody probe. J. Biol. Chem. 274: 12702.

13. Salzer, U., and R. Prohaska. 2001. Stomatin, flotillin-1, and flotillin-2 are major integral proteins of erythrocyte lipid rafts. Blood 97: 1141.

14. SChneider, U., H. U. SCHWEnK, and G. Bornkamm. 1977. Characterization of EBV-genome negative "null" and " $T$ " cell lines derived from children with acute lymphoblastic leukemia and leukemic transformed non-Hodgkin lymphoma. Int. J. Cancer. 19: 521.

15. Korsmeyer, S. J., A. Arnold, A. Bakhshi, J. V. Ravetch, U. Siebenlist, P. A. Hieter, S. O. Sharrow, T. W. LeBien, J. H. Kersey, D. G. Poplack, P. Leder, and T. A. Waldmann. 1983. Immunoglobulin gene rearrangement and cell surface antigen expression in acute lymphocytic leukemias of T cell and B cell precursor origins. J. Clin. Invest. 71: 301.

16. Klein, G., B. Giovanella, A. Westman, J. S. Stehlin, and D. Mumford. 1975. An EBVgenome-negative cell line established from an American Burkitt lymphoma; receptor characteristics. EBV infectibility and permanent conversion into EBV-positive sublines by in vitro infection. Intervirology 5: 319.

17. Steinitz, M., and G. KLEIN. 1980. EBV-transformation of surface IgA-positive human lymphocytes. J. Immunol. 125: 194.

18. HARRIS, N. S. 1974. Plasma cell surface antigen on human blood lymphocytes. Nature 250: 507.

19. Miltenyi, S., W. Muller, W. Weichel, and A. Radbruch. 1990. High gradient magnetic cell separation with MACS. Cytometry 11: 231.

20. Illges, H. 1999. An automated 96-well-plate loader for FACScan. Anal. Cell. Pathol. 19: 99.

21. Cho, Y. J., D. Chema, J. J. Moskow, M. Cho, W. T. Schroeder, P. Overbeek, A. M. BuchberG, and M. Duvic. 1995. Epidermal surface antigen (MS17S1) is highly conserved between mouse and human. Genomics 27: 251.

22. Tang, Z., T. Okamoto, P. Boontrakulpoontawee, T. Katada, A. J. Otsuka, and M. P. LISANTI. 1997. Identification, sequence, and expression of an invertebrate caveolin gene family from the nematode Caenorhabditis elegans. Implications for the molecular evolution of mammalian caveolin genes. J. Biol. Chem. 272: 2437.

23. Galbiati, F., D. Volonte, J. S. Goltz, Z. Steele, J. Sen, J. Jurcsak, D. Stein, L. Stevens, and M. P. LISANTI. 1998. Identification, sequence and developmental expression of invertebrate flotillins from Drosophila melanogaster. Gene 210: 229.

24. Tavernarakis, N., M. Driscoll, and N. C. Kyrpides. 1999. The SPFH domain: implicated in regulating targeted protein turnover in stomatins and other membrane-associated proteins. Trends Biochem. Sci. 24: 425.

25. Harder, T., P. Scheiffele, P. Verkade, and K. Simons. 1998. Lipid domain structure of the plasma membrane revealed by patching of membrane components. J. Cell. Biol. 141: 929.

Dr. Harald Illges, University of Konstanz, Faculty of Sciences, Department of Biology, Immunology, PO Box 5560, M662, 78457 Konstanz, Germany; Tel. +49-7531-882255, Fax +49-7531-883102, e-mail harald.illges@uni-konstanz.de; www.immunologie.uni-konstanz.de, www.bitg.ch 